Faglige udfordringer for fremtidens tandpleje, set i et samfundsodontologisk perspektiv

Christensen, Lisa Bøge; Hede, Børge

Published in:

Aktuel Nordisk Odontologi

DOI:

10.18261/ISSN.2058-7538-2016-01-02

Publication date:

2017

Document version

Også kaldet Forlagets PDF

Document license:

Ikke-specificeret

Citation for published version (APA):

Christensen, L. B., \& Hede, B. (2017). Faglige udfordringer for fremtidens tandpleje, set i et

samfundsodontologisk perspektiv. Aktuel Nordisk Odontologi, 42, 6-17. https://doi.org/10.18261/ISSN.20587538-2016-01-02 


\title{
Faglige udfordringer for fremtidens tandpleje, set i et samfundsodontologisk perspektiv
}

\author{
Lisa Bøge Christensen \\ Odontologisk Institut, Det Sundhedsvidenskabelige Fakultet, \\ Københavns Universitet \\ E-post: Ibch@sund.ku.dk \\ Børge Hede \\ Voksentandplejen i København \\ E-post: gv67@suf.kk.dk
}

\section{Sammendrag}

Tandplejen i de nordiske lande står overfor betydelige udfordringer. På trods af den reducerede forekomst af tandsygdomme har tandplejen svært ved at leve op til sine egne overordnede målsætninger. Dette skyldes den vedvarende sociale polarisering af tandsygdomsforekomsten og udækkede tandplejebehov i særlige befolkningsgrupper. I en tid med betydeligt pres på de offentlige sundhedsudgifter vil det kræve forandringer i tandplejens organisation og personaledimensionering, hvis tandplejens målsætninger skal kunne imødekommes. Det er dog tvivlsomt, om en sådan forandring kan ske, når den største del af tandplejen fungerer på efterspørgselsstyrede markedsvilkår.

Emneord Tandplejens mål, tandplejesystemet, oral epidemiologi, brug af tandplejesystemet, prognose

\section{Summary}

The oral health care systems in the Nordic countries will face considerable future challenges. Although the prevalence of oral diseases has been reduced, social inequality in oral health still persists. In addition, disadvantaged population groups apparently have a high level of untreated oral diseases. This makes it difficult to fulfill the aims of the oral health care system, aims established by the health authorities in each country. The resources allocated for health and health care are, however, under strain, and to reach the aims some changes are required, i.e. change of the structure is needed including changes of 
the distribution of manpower in the oral health system. However, the oral health care system is based, at least for adults, on market mechanisms in terms of demand of oral care from the patients. Therefore, reaching the aims of the oral health care system is a challenge.

Keywords Oral health care goals, oral health care system, oral epidemiology, use of the oral health care system, prognosis

\section{Indledning}

Ideelt set bør organisering og dimensionering af et behandlings- og forebyggelsestilbud tage udgangspunkt i sygdomsforekomst, forekomst af risikofaktorer samt behandlings- og forebyggelsesmuligheder, individuelt såvel som på populationsplan. Imidlertid er fremtiden for det begreb, som vi kalder «tandplejen», afhængig af mange andre forhold end udviklingen i det odontologiske sygdomspanorama og mulighederne for behandling og forebyggelse. Det skyldes blandt andet, at «tandplejen» ikke kan betragtes som en samlet organisation, men snarere en konstruktion med mange forskellige aktører med forskellige mål. Dette skønt der i lovgivningen i de skandinaviske lande allerede i 1980erne blev defineret klare overordnede mål for «tandplejen» (Fig. 1).

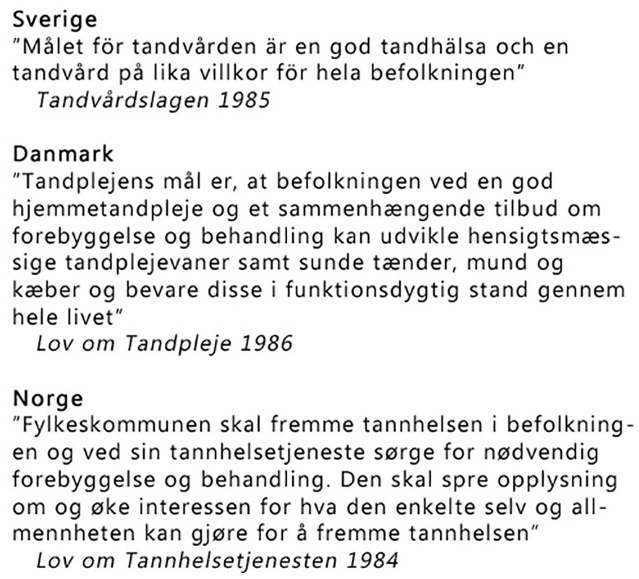

Figur 1. Formål for tandplejen i de tre skandinaviske lande. 
Disse mål er karakteriseret ved at anlægge et befolkningsperspektiv frem for et individuelt perspektiv og understreger såvel et lighedsprincip som et ønske om forebyggelse og sundhed og ikke kun behandling af sygdom.

I samtlige nordiske lande eksisterer der en meget betydelig privat tandplejesektor, som ikke umiddelbart lader sig styre i retning af de mål, som de offentlige myndigheder har opstillet. Den private sektor lader sig kun til en vis grad regulere, idet de ydelser, som leveres, primært er finansieret af patienternes egenbetaling, og derfor er et anliggende mellem den enkelte behandler og patienten.

\section{Incitament til målopfyldelse}

Indenfor den private sektor, som er efterspørgselsstyret, er det derfor i højere grad befolkningens efterspørgsel efter tandpleje, som er styrende for aktiviteterne og ikke de offentlige myndigheders fastsatte målsætninger. Myndighederne kan påvirke efterspørgslen i en bestemt retning gennem forskellige incitamenter, som $\mathrm{fx}$ differentieret økonomisk subsidiering af bestemte ydelser til specifikke patientgrupper eller til behandling af specifikke lidelser. Men myndighederne har kun ringe indflydelse på, hvad de behandlingsmæssige ressourcer faktisk anvendes til, og om de anvendes hensigtsmæssigt i forhold til de overordnede målsætninger for tandplejen.

De lighedsbetragtninger og det befolkningsperspektiv, som bl.a. indgår i flere af de nævnte målsætninger (Fig. 1) lader sig ikke nødvendigvis realisere, når tandpleje er efterspørgselsstyret og udbydes på markedsvilkår til den største del af befolkningen, også selvom man ved aftaler søger at koble den offentlige subsidiering med de overordnede målsætninger (Fig. 2).

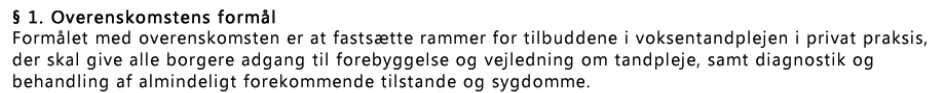

Figur 2. Formålsparagraffen i den danske overenskomst mellem Tandlægeforeningen og Regionernes Iøn- og takstnævn om tandlægehjælp. 
Dette fordrer bl.a., at tilskudsstrukturen indeholder tilstrækkelige incitamenter for både behandlere og patienter til at forfølge de overordnede mål. Der kan på den anden side opstå barrierer, såfremt der kun er en ringe subsidiering, eller hvis subsidiering og honorarstruktur ikke tilgodeser de ydelser, som understøtter målopfyldelsen, $\mathrm{fx}$ forebyggende ydelser eller incitament/mulighed for opsøgende virksomhed overfor udsatte grupper.

Manglende regelmæssig brug af tandplejesystemet skyldes tilsyneladende en række dybereliggende faktorer og kan måske kun ændres, hvis tandplejesystemets struktur undergår forandringer. Fx er der kun tilskud til visse basale tandplejeydelser i Danmark, og dette gælder med få undtagelser for alle voksne uanset sygdomsforekomst. Tilskuddet dækker mindre end en tredjedel af udgiften til de overenskomstmæssige ydelser. Der er for eksempel ikke tilskud til lokalanæstesi eller røntgenoptagelser (med undtagelse af bitewings). Tilskudsstrukturen er i højere grad historisk bestemt end ud fra et perspektiv om målopfyldelse.

\section{Ressourceanvendelse}

De ressourcer, der allokeres, er derfor i højere grad reguleret af de enkelte befolkningsgruppers efterspørgsel efter tandpleje end af et overordnet hensyn til, hvilke befolkningsgrupper, der har det største behov for forebyggelse, behandling og nødvendig rehabilitering. Såfremt der opstår en trend i retning af en bestemt form for odontologisk forskønnelse uden egentlig sundhedsmæssig værdi, vil denne trend kunne beslaglægge betydelige behandlingsressourcer, som mere hensigtsmæssigt kunne anvendes andetsteds. Det er en udfordring i sig selv, hvis kompetent personale er en mangel.

\section{Manglende politisk bevågenhed}

Tandplejen vil i stigende grad blive påvirket af generelle samfundsmæssige megatrends i de nordiske samfund, hvor 1900-tallets velfærdsstat ser ud til at være under forandring mod det 21. århundredes konkurrencestat (1). Det betyder en strammere politisk priori- 
tering og en stadig hårdere kamp om de begrænsede offentlige ressourcer. Skønt undersøgelser har vist, at bevarelse af tænderne bliver tillagt stor betydning i befolkningen (2), fylder tandpleje sjældent ret meget i den politiske debat - måske fordi tandsygdomme ikke er dødelige og kun sjældent er invaliderende i betydelig grad. Tandplejen har således en betydelig udfordring både nu og i fremtiden med hensyn til at dokumentere betydningen af odontologiske lidelser, deres behandling og forebyggelse med henblik på at bevare legitimitet i befolkningen, og især blandt de politiske meningsdannere og beslutningstagere. Tandplejen og specielt den odontologiske forskning har her en betydelig udfordring med hensyn til at dokumentere tandplejens effekt, værdi og betydning for den generelle helbredstilstand og den enkelte borgers livskvalitet.

\section{Formål}

På trods af ovenstående betragtninger har vi alligevel i nærværende artikel valgt primært at beskrive tandplejens udfordringer med udgangspunkt i en epidemiologisk fremskrivning af udviklingen i tandsygdommene blandt børn, voksne, ældre og særlige grupper. Derudover har vi søgt at nuancere tandplejens udfordringer i relation til de samfundsmæssige trends og det faktum, at tandplejen som profession er i økonomisk konkurrence. Begge forhold vil have en betydelig indflydelse på tandplejens fremtidige udfordringer og ikke mindst muligheden for realistiske løsninger.

\section{Børn og unge}

Generelt har der været en jævnt nedadgående tendens med hensyn til forekomst af caries blandt børn og unge i såvel de nordiske lande som i resten af den vestlige verden (3). Denne reduktion er sket over de sidste 30-40 år. For eksempel havde 60 \% af 15-årige danske børn i 2015 hverken ubehandlet eller behandlet caries, i 1997 var det tilsvarende tal $30 \%$ og i 1988 kun $12 \%$. Det samme mønster ses i studier fra andre nordiske og vestlige lande. Samtidig er der sket en 
såkaldt polarisering af cariesforekomsten blandt børn og unge, hvilket betyder, at det er en mindre del af børne- og ungdomspopulationen, der bærer størstedelen af sygdomsbyrden (caries). I en række nordiske studier er det påvist, at bl.a. forældrenes uddannelsesniveau og familiens indkomst har sammenhæng med forekomsten af caries hos børn og unge, ligesom migration har en sammenhæng med øget forekomst af tandsygdomme (4-8). Med hensyn til caries er det en risikofaktor at tilhøre en etnisk minoritetsgruppe, men der er dog tale om inhomogene grupper med forskelligt sprog, kulturelle vaner og karakteristika (9). Dette er naturligvis en særlig udfordring for tandplejens forebyggende indsats.

\section{Voksenbefolkningen}

Tandstatus hos voksne måles oftest som den gennemsnitlige samlede carieserfaring $(\mathrm{DMFT}=$ summen af carierede, mistede og fyldte tænder). Den gennemsnitlige carieserfaring hos 35-44-årige europæere er høj i forhold til resten af verden. Der er dog generelt sket betydelige forbedringer af voksnes tandstatus. Der er sket et dramatisk fald i antallet af tandløse i den vestlige verden - også i de nordiske lande, hvor studier peger i samme positive retning, dvs. tandløsheden er reduceret betydeligt, og den voksne befolkning har langt flere tænder end tidligere (10-12). Desuden er det vist, at de ældre generationer har et stigende forbrug af tandpleje, og at der bliver flere og flere regelmæssige brugere i den ældre del af befolkningen.

Der ses også et stort behov for vedligeholdelse af restaureringer samt et øget behov for parodontale tandplejeydelser blandt ældre borgere (13). Forekomsten af marginal parodontitis ses også at være betydelig i de øvrige nordiske landes ældrebefolkning.

Samtidig med forbedringen af tandsundheden er der imidlertid mange undersøgelser, der peger på en skæv fordeling af tandsygdomme (14). Den dårligste tandstatus og de fleste tandsygdomme synes at ophobe sig i den del af befolkningen, der har den laveste sociale status. Man kan således hævde, at tandsygdommene er på vej væk fra at være en folkesygdom, og til en vis grad nærmer sig at 
være et socialt stigma (15). Den øgede polarisering, som er set med hensyn til forekomst af tandsygdomme, ser desuden ud til at hænge sammen med manglende brug af tandplejen. Det vil i praksis sige, at man ofte finder den største tandsygdomsbyrde i den del af voksenbefolkningen, som ikke eller kun sjældent søger tandlæge. I denne risikogruppe vil man desuden ofte møde socialt udsatte voksne.

\section{Særlige grupper}

I takt med den generelt forbedrede tandsundhedstilstand er det blevet tydeligere, at nogle befolkningsgrupper ikke i samme omfang har haft glæde af den positive udvikling. Ud over den sociale gradient med hensyn til tandsundhed og tandpleje er der grupper i samfundet, som ikke drager fordel af den efterspørgselsstyrede tandpleje. Det drejer sig om grupper med ringe egenomsorg og handlekompetence, specielt svage ældre, udviklingshæmmede, sindslidende, stofmisbrugere og hjemløse - socialt marginaliserede. WHO adresserede allerede dette problem i sin globale politik for tandpleje fra 2007 (Fig. 3).

\footnotetext{
"The WHO Global Oral Health Programme gives priority to the organization of oral health services that matches the needs of the population. In several industrialized Western countries, oral health services are made available to the population, either based on public or private systems.
}

Meanwhile, people in deprived communities, homebound and disabled individuals, old-age persons, and certain ethnic minorities are not sufficiently covered by oral health care.

Social inequality in oral health status and use of services is somewhat universal, even in the Nordic countries with public responsibilities in financing and delivery of oral health care, remarkable differences are observed by social class.

Outreach services may be necessary to tackle the burden of poor oral health of people with limited resources and lack of tradition of regular oral health care."

Figur 3. Udvikling og justering af tandplejetjenester ifølge WHO. 
Der er dokumenteret betydelig tandsygdomsforekomst blandt funktionssvækkede ældre, både plejehjemsbeboere og hjemmeplejeklienter (16). Den orale sundhedstilstand synes relateret til graden af funktionsnedsættelse. Der ses en øget cariestilvækst og en betydelig oplevet belastning som følge af orale tilstande udtrykt ved Oral Health-Related Quality of Life. Der ses også generelt store problemer med mundhygiejnen.

Blandt voksne udviklingshæmmede synes de dårligst fungerende at have en lavere cariestilvækst, men de har alligevel det største tandtab, da sygdomstilstande i denne gruppe progredierer udiagnosticerede. Internationale oversigtsartikler (17) konstaterer en forøget forekomst af parodontale lidelser blandt udviklingshæmmede, når disse sammenlignes med normalbefolkningen: Carieserfaringen (DMFS/DMFT) er som i normalbefolkningen eller måske endog lavere. Dette gælder dog ikke forekomsten af ubehandlet caries, som er forøget blandt udviklingshæmmede. Gruppen med Down syndrom viser særlige parodontale problemer.

Undersøgelser viser samstemmende et forøget tandtab og forøget carieserfaring blandt personer med langvarige psykiatriske lidelser (18). Dette skyldes uregelmæssige tandlægebesøg, hyposiali pga. medicinering og mangelfulde tandbørstevaner. Endvidere ses dårlig tandsundhedstilstand og en mangelfuld benyttelse af den efterspørgselsorienterede tandpleje blandt stofmisbrugere og blandt hjemløse.

Fælles for alle disse grupper er, at de ikke eller kun vanskeligt kan benytte en efterspørgselsorienteret tandpleje. Der er således en udfordring i at udvikle særlige tandplejetilbud til disse grupper. Tilbud som kan tilgodese deres specielle behov. Hertil knytter der sig dog problemer bl.a. vedr. afgrænsning af målgruppen, indholdet i tandplejetilbuddet samt estimering af den enkeltes behov for tandpleje (19). Det er en betydelig udfordring for tandplejen at udvikle virksomme programmer for disse befolkningsgrupper og at evaluere, om sådanne programmer, og eventuelt allerede eksisterende programmer, har den tilsigtede effekt på tandsundheden. 


\section{Behandlingsmønster i voksenbefolkningen}

Over halvdelen af alle tandplejeydelser til danske borgere i aldersgruppen 64-65 år udgøres af tandundersøgelser og/eller ydelser af forebyggende karakter (13), som ifølge WHO kaldes lavteknologiske opgaver. Ifølge WHO hører konserverende parodontalbehandling desuden til de lavteknologiske ydelser, og det skønnes derfor, at ca. $70 \%$ af ydelserne til 64-65-årige hører til de lavteknologiske ydelser. Da det forudses, at den største behandlingsbyrde i fremtiden vil være at finde hos den midaldrende og ældre befolkning, er det sandsynligt, at de lavteknologiske ydelser vil udgøre en endnu større andel af det samlede antal ydelser blandt samtlige voksne.

Samlet set vil en meget stor del af tandplejens opgaver være af en sådan karakter, at de i stort omfang vil kunne varetages af tandplejere. Tandplejen vil derfor ud fra et såkaldt LEON princip (Laveste Effektive Omkostnings Niveau) blive mødt med et krav om en betydelig opgaveglidning fra tandlæger til personalegrupper med kortere uddannelse, hvilket vil betyde en ændring i tandplejens personaledimensionering. Dette udgør såvel en uddannelsespolitisk som en organisatorisk udfordring for tandplejen.

\section{Kan de store udfordringer imødegås?}

Den største udfordring for tandplejen som helhed er at leve op til de mål, som blev opsat allerede i sidste århundrede. Specielt synes den betydelige socialt betingede ulighed i tandsundhed og de uløste problemer i samfundets marginalgrupper at påkalde sig opmærksomhed. Derudover synes den positive udvikling i tandsundhed hos flertallet af befolkningen at nødvendiggøre en anden sammensætning af tandplejens arbejdsstyrke.

Det vil være relevant at spørge, hvordan man kan nå de ressourcesvage grupper med hensyn til at fremme deres tandsundhed. Men hensyn til forekomst og udvikling af caries er der ofte tale om underliggende samfundsstrukturer og årsager, som ikke lader sig ændre uden videre (20). Det er foreslået, at man i det forebyggende 
arbejde fokuserer mere på de geografiske områder, hvor tandsundhedstilstanden er ringe fremfor at fokusere på familiernes sociale og kulturelle status (21). Opgaven med at nå alle med hensyn til forebyggelse af tandsygdomme, når det eksempelvis gælder børn og unge, løses næppe ved blot at fortsætte den hidtidige praksis - der bør tænkes i mere utraditionelle baner. Man kunne eksempelvis lægge mere og særlig vægt på en strategi for sundhedsfremmende tiltag på populationsniveau fremfor den individuelt rettede metode, som typisk foregår ved tandlægestolen. Der er fordele og ulemper ved begge typer af forebyggelsesstrategi. Det fremhæves ofte, at det er spild af ressourcer at anvende populationsstrategi, når der er mange helt uden caries, og caries ikke er normalfordelt i populationen. Men da det er uklart, hvem der vil udvikle caries, er det gavnligt, at populationsstrategi rammer bredt (22).

Med hensyn til de socialt udsatte og samfundets øvrige marginalgrupper kunne man forestille sig en struktur, hvor man flyttede ressourcerne fra den del af befolkningen, som ikke fejler noget eller meget lidt, over til den gruppe, der er belastet af tandsygdomme. Det er dog næppe sandsynligt, at en øget økonomisk subsidiering til socialt dårligt privilegerede alene er løsningen på dette problem, men at man må afprøve andre modeller med højere grad af opsøgende elementer. Det bør under alle omstændigheder få nogle praktiske konsekvenser, at mange fejler intet eller meget lidt, og andre derimod er tungt belastet af orale sygdomsproblemer. Den svenske model for voksentandplejen kunne fremhæves, idet der er tale om et system, der beskytter det enkelte individ mod meget store tandplejeudgifter. Man kunne fristes til at tro, at det lave niveau for tandløshed i Sverige hænger sammen med dette system. En forhindring for indførelse af et sådant system andre steder kunne være, at det i opstarten formentlig vil betyde større offentlige udgifter. En sådan hindring forstærkes yderligere af, at tandplejen generelt er isoleret i forhold til det øvrige sundhedsvæsen, og dermed er i fare for at blive prioriteret lavt.

Men som den danske humorist Storm P har sagt: «Det er svært at spå... især om fremtiden...». Det gælder også hvad angår tandplejens fremtidige udfordringer. 


\section{Referencer}

1. Pedersen OK. Konkurrencestaten. København: Hans Reitzels Forlag; 2011.

2. Hede B, Vigild M, Linneberg A. Tandsygdomme som helbredsproblem blandt danskere. Tandlægebladet 2003; 107: 324-8.

3. Marthaler TM. Changes in dental caries 1953-2003. Caries Res 2004; 38: 173-81. DOI:10.1159/000077752

4. Stecksen-Blicks C, Kieri C, Nyman JE, Pilebro C, Borssen E. Caries prevalence and background factors in Swedish 4-year-old children - a 40year perspective. Int J Paediatr Dent 2008; 18: 317-24. DOI:10.1111/ j.1365-263X.2008.00929.x

5. Wigen TI, Wang NJ. Caries and background factors in Norwegian and immigrant 5-year-old children. Community Dent Oral Epidemiol 2010; 38: 19-28. DOI:10.1111/j.1600-0528.2009.00502.x

6. Christensen LB, Twetman S, Sundby A. Oral health in children and adolescents with different socio-cultural and socio-economic backgrounds. Acta Odontol Scand 2010; 68: 34-42. DOI:10.3109/00016350903 301712

7. Vehkalahti M, Tarkkonen L, Varsio S, Heikkila P. Decrease in and polarization of dental caries occurrence among child and youth populations, 1976-1993. Caries Research 1997; 31: 161-5.

8. Kallestal C, Wall S. Socio-economic effect on caries. Incidence data among Swedish 12-14-year-olds. Community Dent Oral Epidemiol 2002; 30: 108-14. DOI:10.1034/j.1600-0528.2002.300204.x

9. Dhawan N, Bedi R. Transcultural oral health care: 6 . The oral health of minority ethnic groups in the United Kingdom--a review. Dent Update 2001; $28: 30-4$.

10. Holst D, Schuller AA. Oral health in a life-course: Birth-cohorts from 1929 to 2006 in Norway. Community Dent Health 2012; 29: 134-43.

11. Hugoson A, Koch G. Thirty year trends in the prevalence and distribution of dental caries in Swedish adults (1973-2003). Swed Dent J 2008; 32: 57-67.

12. Petersen $\mathrm{PE}$, Ekholm $\mathrm{O}$, Jürgensen $\mathrm{N}$. Overvågning af voksenbefolkningens tandstatus og tandlægebesøg i Danmark. Tandlægebladet 2010; 114: 480-91.

13. Christensen LB, Rosing K, Lempert SM, Hede B. Patterns of dental services and factors that influence dental services among 64-65-year-old 
regular users of dental care in Denmark. Gerodontology 2016; 33: 7988. DOI:10.1111/ger.12122

14. Schwendicke F, Dorfer CE, Schlattmann P, Foster PL, Thomson WM, Paris S. Socioeconomic inequality and caries: a systematic review and meta-analysis. J Dent Res 2015; 94: 10-8. DOI:10.1177/0022034514557 546

15. Christensen LB, Hede B, Rosing K, Özhayat EB. Caries fra folkesygdom til stigma? Tandlægebladet 2013; 117: 204-11.

16. De Visschere LM. The development and application of an oral health care model for institutionalized older people. Thesis. Gent, Belgium: University of Gent 2010.

17. Anders PL, Davis EL. Oral health of patients with intellectual disabilities: a systematic review. Spec Care Dentist 2010; 30: 110-7. DOI:10.1111/j.1754-4505.2010.00136.x

18. Kisely S, Baghaie H, Lalloo R, Siskind D, Johnson NW. A systematic review and meta-analysis of the association between poor oral health and severe mental illness. Psychsom Med 2015; 77: 83-92. DOI:10.1097/ PSY0000000000000135 (Epub ahead of print).

19. Hede B. Tandplejens stedbørn - de udsatte og de udstødte. Tandlægebladet 2015; 119: 794-801.

20. Sisson KL. Theoretical explanations for social inequalities in oral health. Community Dent Oral Epidemiol 2007; 35: 81-8. DOI:10.1111/j.1600-0528.2007.00354.x

21. Locker D. Deprivation and oral health: a review. Community Dent Oral Epidemiol 2000; 28: 161-9. DOI:10.1034/j.1600-0528.2000.280301.x

22. Rose G. The strategy of preventive medicine. Oxford, UK: Oxford Medical Publications; 1992. 